\title{
- Effect of Indian Obesity parameters on Asthma Control Among Patients Attending Tertiary Care Centre \\ IJCRR \\ Section: Healthcare
} ISI Impact Factor (2019-20): 1.628 IC Value (2019): 90.81 $\operatorname{SJIF}(2020)=7.893$

(c) (7) (8) Copyright@IJCRR

\section{Vimal Raj $\mathbf{R}^{\mathbf{1}}$, Pajanivel $\mathbf{R}^{\mathbf{2}}$}

'Assistant Professor, Department of Pulmonary Medicine, Ground floor, D-block, Hospital Main building, Mahatma Gandhi Medical College \& Research Institute, Sri Balaji Vidyapeeth, Pondicherry, Pondicherry 607403, India; ${ }^{2}$ Professor \& HOD, Department of Pulmonary Medicine, Ground floor, D-block-Hospital Main building, Mahatma Gandhi Medical College \& Research Institute, Sri Balaji Vidyapeeth, Pondicherry, Pondicherry 607403, India.

\section{ABSTRACT}

Background: The impact of abdominal obesity as defined by Indian obesity parameters on asthma symptom control has not been evaluated in detail.

Objective: To correlate asthma symptom control with body mass index and waist circumference.

Methods: Asthma patients who attended the outpatient department or were admitted to our tertiary care hospital between June 2018 and May 2019 were investigated for asthma severity, asthma symptom control, and correlated with the obesity parameters, including waist circumference, based on Indian and WHO criteria.

Results: Of the 110 patients, 56.3\% (62 patients) were female. There was a significant worsening of asthma symptom control among overweight and obese patients, diagnosed using Indian Body Mass Index (BMI) classification, as compared to those with normal BMI $(p=0.04)$. But when the WHO BMI classification was used, the correlation was not statistically significant (two-tailed $\mathrm{p}$-value $=0.10$; Fisher's exact test). Patients who were classified obese as per Indian criteria had an 8 times more risk of having uncontrolled /partly controlled asthma as compared to those with normal Indian BMI ( $p=0.027 ; \mathrm{OR}=8.42 ; 95 \% \mathrm{Cl}=1.2-55.42)$. Partly controlled or uncontrolled asthma was noted in $93.3 \%$ (56/60) of those patients, who had normal waist circumference as per WHO criteria but were diagnosed with abdominal obesity as per Indian criteria.

Conclusion: Waist circumference is a simple but important parameter to be assessed among obese asthmatics. Indian BMI and waist circumference parameters are found to be better in assessing asthma symptom control among our population than World Health Organization standards.

Key Words: Asthma, Abdominal obesity, Body mass index, Leptin, Spirometry, Waist circumference

\section{INTRODUCTION}

In India, approximately $30-65 \%$ of the adult urban population are either overweight, obese or have abdominal obesity. ${ }^{1}$ The rising prevalence of metabolic syndrome and cardiovascular diseases (CVD) in the Indian subcontinent has a direct relationship with the rising prevalence of obesity and overweight. ${ }^{1}$ Asian Indians have a higher percentage of body fat, abdominal adiposity at lower or similar body mass index (BMI) levels as compared to Caucasians. ${ }^{1}$ Obesity is a proven risk factor in the development of asthma. ${ }^{2}$ Compared to adults with normal BMI, asthma is more prevalent among obese ${ }^{2,3}$ and obesity in- creases the incidence of asthma by $2.0-2.3$ fold in children and adults respectively. ${ }^{3,4}$ As they exhibit a different (eg: less atopic) inflammatory phenotype,${ }^{5}$ obese asthmatics often have poorly controlled asthma. ${ }^{6,7}$ Excess abdominal fat may be an important risk factor for asthma, but measures of central obesity have been assessed in only a handful of studies. ${ }^{8-10}$

No study to date has evaluated the prevalence of abdominal obesity among asthmatics in the Indian population using Indian Obesity parameters and their implications on asthma control. Hence it is done as an explorative study.

\section{Corresponding Author:}

Vimal Raj R, Assistant Professor, Department of Pulmonary Medicine, Ground floor, D-block, Hospital Main building, Mahatma Gandhi Medical College \& Research Institute, Sri Balaji Vidyapeeth, Pondicherry, Pondicherry 607403, India; Phone: + 91413 - 2615449; Fax: +91413-2615457; Email: iniyaulagam@ymail.com

ISSN: 2231-2196 (Print) ISSN: 0975-5241 (Online)

Received: $09.08 .2020 \quad$ Revised: 28.11 .2020 Accepted: 03.01.2021 Published: 25.04 .2021 


\section{MATERIALS AND METHODS}

\section{Patients}

Between June 2018 and May 2019 all patients above the age of 18 years, attending outpatient department / admitted under Pulmonary Medicine with cough, breathlessness, chest tightness, and history of wheeze that vary over time and in intensity (along with previously diagnosed asthmatics) were enrolled for the study after their spirometry is suggestive of asthma and if they satisfied the BMI or Abdominal obesity criteria of 2009 Asian Indian-specific overweight, obesity and abdominal obesity consensus statement. ${ }^{1}$ Written informed consent was obtained from all patients. Those who are in exacerbation, pregnant women, and patients who were unable to perform spirometry were excluded from the study.

\section{Procedure}

The diagnosis of asthma was based on the Global Initiative for Asthma (GINA) guidelines 2018 wherein cough, chest tightness, shortness of breath, and wheezing are considered as the characteristic symptoms along with variable expiratory airflow limitation defined as reduced FEV1/FVC and $>12 \%$ and $>200 \mathrm{ml}$ increase in FEV1 from the baseline, after administration of 200 - $400 \mathrm{mcg}$ of salbutamol or equivalent, while performing spirometry. ${ }^{11}$ Spirometry was performed using a reusable turbine sensor spirometer (MIR Spirobank $\mathrm{II}{ }^{\circledR}$ basic, Italy). Spirometric severity was classified as per the European Respiratory Society/American Thoracic Society (ERS/ATS) lung function tests interpretation $2005 .{ }^{12}$ The patients were classified as having mild, moderate, moderately severe, severe, and very severe asthma based on the following FEV1 cut-offs: > 70\%, 60-69\%, 50-59\%, 35-49\% and less than $35 \%$ respectively.

Weight $(\mathrm{kg})$ and Height $(\mathrm{cm})$ were measured and BMI was derived from the weight in kilogram upon height in metre. ${ }^{2}$ Waist circumference (WC) was measured using non-stretchable flexible tape in the horizontal position, at the midpoint of the iliac crest and the lowermost rib, at the end of normal expiration, in the fasting state, with the subject standing erect and the observer by the side.Normal BMI range as per the 2009 Asian-Indian Obesity consensus statement was $18.0-22.9 \mathrm{~kg} / \mathrm{m}^{2}$, overweight: $23.0-24.9 \mathrm{~kg} / \mathrm{m}^{2}$ and obesity: $>25 \mathrm{~kg} / \mathrm{m}^{2}$. Abdominal obesity was defined in the consensus statement as WC above $80 \mathrm{~cm}$ in females and $90 \mathrm{~cm}$ in males $^{1}$ in contrast to the WHO defined criteria of $>88 \mathrm{~cm}$ in females and $>102 \mathrm{~cm}$ in males. ${ }^{13}$ Normal BMI range defined by WHO is between 18.5 and $24.9 \mathrm{~kg} / \mathrm{m}^{2}$. BMI above $30 \mathrm{~kg} /$ $\mathrm{m}^{2}$ is defined as obesity while the intermediate category is defined as overweight. ${ }^{14}$

Asthma Control was assessed using the 2018GINA classification of asthma symptom control over the last 4 weeks. It comprises of 4 clinical parameters namely, more than twice per week daytime asthma symptoms, any night waking due to asthma, more than twice per week reliever medication requirement for symptoms, and any activity limitation due to asthma, wherein the patients have to convey whether they experience any of the symptoms or no symptom at all (1 point for every symptom present). Based upon the outcome they were categorized as having well-controlled (none of the parameters of clinical worsening was present), partly controlled (1-2 of the parameters), or uncontrolled asthma (3-4 of the parameters). In a newly diagnosed case willing to participate in the study, BMI/WC measurement was done on day 1 along with spirometry while the GINA assessment tool was used after a 4 week follow up period. Among the patients who were already on follow up with the institute, the first visit during the study period was considered for assessing the previous 4 weeks symptom control along with BMI / WC calculation and spirometry was performed during the study period. All new patients were initiated on either Dry Powder Inhaler (DPI) or Metered Dose Inhaler (MDI) therapy \pm spacer. The treatment comprised of Inhaled Corticosteroid (ICS) \pm LongActing Beta 2 agonist (LABA) with either ShortActing Beta2 Agonist (SABA) or low dose ICS/ Formoterol as a reliever, as per GINA guidelines. ${ }^{11}$ The study was conducted in line with the Declaration of Helsinki and was approved by the Institutional Human Ethics Committee, Sri Balaji Vidyapeeth, Pondicherry, India.

\section{Statistical analysis}

We have used IBM SPSS ver. 16.0 (IBM Co., Armonk, NY, USA). Multiple logistic regression analyses and Fisher's exact test were done to compare the correlation between asthma symptom control, asthma severity, and various parameters like BMI, WC, etc. p-value $<0.05$ was considered to be statistically significant.

\section{RESULTS}

Data obtained from one hundred and ten asthmatics were analyzed. The baseline data of the patients are given below (Table 1). The mean age of all the patients was $40.3 \pm 9.81$ years. The number of female patients was slightly higher than males [62 (56.3\%) vs $48(43.7 \%)]$. While the mean weight of the patients was $70.05 \pm 10.07 \mathrm{~kg}$, the mean height was $157.75 \pm 8.04 \mathrm{~cm}$. The mean BMI of the patients was $28.2 \pm$ 4.01, which is obesity, according to the Indian BMI criteria whereas World Health Organization's (WHO) classification defines it as overweight $\left(25-29.9 \mathrm{~kg} / \mathrm{m}^{2}\right)$. The mean FEV1/ FVC of the study population was $<70 \%(68.59 \pm 10.74)$, in which the FVC was fairly preserved $(82.27 \pm 13.22)$ while the $\%$ predicted FEV1 was less than $60 \%(58.48 \pm 11.6)$.

\section{BMI vs Asthma Control}

Classification of patients based on both Indian and WHO BMI criteria and their asthma symptom control is given in 
Table 2. More than three-fourths of the patients were obese as per the Indian BMI classification (78.17\%). Among them, nearly two-thirds (73 patients, $66.36 \%$ ) had either partially controlled or uncontrolled asthma symptoms whereas, only 13 patients $(11.81 \%)$ had well-controlled asthma. In the overweight category, $14(12.72 \%)$ had partly controlled or uncontrolled asthma while only $5(4.54 \%)$ had well-controlled asthma. As per the Indian BMI classification, 5 patients were in the normal BMI $\left(18.0-22.9 \mathrm{~kg} / \mathrm{m}^{2}\right)$ category but were included in the study due to abdominal obesity (WC $>80 \mathrm{~cm}$ in females and $90 \mathrm{~cm}$ in males). Among them, 3 had well-controlled asthma and 2 had partly controlled/ uncontrolled asthma. The difference in the asthma symptom control among different BMI categories was found to be statistically significant which implies that overweight and obese individuals (Indian classification) had either partly controlled/uncontrolled asthma during the last 4 weeks (twotailed $p$-value $=0.042$; Fisher's exact test).In contrast, while applying WHO BMI criteria, the poor asthma control noted among 73 patients $(66.35 \%)$ within the overweight and obese population was not statistically significant (two-tailed p-value $=0.105$; Fisher's exact test).

Indian overweight individual has 4.2 times higher chances of having partly controlled/uncontrolled asthma as compared to the normal BMI individual, but it was not statistically significant $(p=0.172 ; O R=4.2 ; 95 \% C I=0.54-32.96)$. Similarly, a patient who is obese as per Indian criteria has an 8 times more risk of having uncontrolled / partly controlled asthma as compared to a patient with normal Indian BMI $(\mathrm{OR}=8.42$; $95 \% \mathrm{CI}=1.28-55.42)$ (Figure 1).

\section{Waist Circumference vs Asthma Control}

Out of the 110 patients, $104(94.5 \%)$ had either partially controlled or uncontrolled asthma symptoms (Table 3). Sixty $(54.5 \%)$ patients had normal waist circumference as per WHO criteria. Among them, though 56patients $(93.3 \%)$ had partly controlled or uncontrolled asthma, it was not found to be statistically significant (Fisher exact test, two-tailed $\mathrm{P}$ value $=0.69)($ Figure 2).

\section{The severity of asthma vs Asthma Control:}

Even in patients with fewer symptoms, FEV $1<60 \%$ predicted has a high risk of exacerbations as per GINA guidelines. In our study, 48 patients (43.63\%)had FEV1<60\%. Out the $48,44(91.66 \%)$ had poor asthma symptom control (partly controlled/uncontrolled) (Table 4). Even among those 62 patients $(56.36 \%)$ who had FEV $1>60 \%$ predicted, only $17(27.42 \%)$ patients had well-controlled asthma while the rest (45 patients, $72.58 \%$ ) had either partially controlled or uncontrolled asthma. The poor asthma control noted among patients with FEV1 $<60 \%$ (moderately severe, severe, and very severe obstruction, as per ATS / ERS lung function test interpretation, 2005) was found to be statistically significant (two-tailed p-value $=0.0141$, Fisher exact test) $($ Figure 3 ). The odds of asthmatics with low FEV1 predicted $(<60 \%$ predicted) having poor asthma control are 4 times more than those who have FEV1 predicted $>60 \%(\mathrm{OR}=4.16 ; 95 \% \mathrm{CI}=$ 1.3 to 13.33 ), thereby highlighting the importance of regular spirometric assessment among asthmatics, complimenting clinical evaluation.

\section{DISCUSSION}

While there are studies that assessed the relationship between abdominal obesity and asthma contro ${ }^{15}$, there is hardly any study that considered the Indian waist parameters and their impact on asthma severity and asthma symptom control among the Indian population. Though the difference in body fat percentage of Asians, increased risk factors for type 2 diabetes mellitus and cardiovascular diseases were appreciated by WHO, as of now, only different cut-offs points for taking action were suggested by the WHO as the available data do not necessarily indicate one clear BMI cut-off point for all Asians for overweight or obesity. ${ }^{16} \mathrm{Hence}$ it is imperative to provide clinical research data to make informed decisions regarding the region and ethnicity-specific BMI and abdominal obesity cut off points and their impact on major clinical disease entities like asthma, cardiovascular diseases, type 2 diabetes mellitus, etc.

Concerning BMI and asthma control as per GINA 2018 assessment tool, we have found that the risk of having poor asthma control is high among the obese and overweight patients $(\mathrm{OR}=4$ and 8 for overweight and obese patients respectively) as compared to those with normal BMI, as per Indian criteria. The results were similar to a study by Mosen et al. which showed that obese individuals with persistent asthma were more likely to have worse asthma control than those with normal BMI, as per WHO standards. ${ }^{6}$ But they didn't find any correlation between overweight individuals and adverse outcomes like asthma control, asthma-related admissions, etc. Jesus JPV et al. in their study had similar results. ${ }^{17}$ In their study they used WHO BMI cut-offs whereas abdominal adiposity was assessed using International Diabetes Federation criteria based on South Asian parameters for Central and South Americans $(>90 \mathrm{~cm}$ for males and $>80$ $\mathrm{cm}$ for females). ${ }^{16}$

$\mathrm{Lv}$ et al. in their study found out that abdominal adiposity correlated with poorer asthma control among uncontrolled asthmatics. ${ }^{19}$ They used the waist-to-height ratio for abdominal adiposity assessment. Another study from Japan stated that only the abdominal visceral fat area assessed by computed tomography (CT) of the abdomen showed a negative association with the Asthma Quality of Life Questionnaire in males. ${ }^{10}$ We used waist circumference for the assessment of abdominal obesity as it was proposed along with waist- 
hip ratio (WHR), by the WHO in their expert consultation on abdominal obesity. ${ }^{13} \mathrm{~A}$ recently concluded meta-analysis on asthma and abdominal obesity considered studies using waist circumference only as this was found to be the method used in all the analyzed studies, whereas only a few studies used WHR and the waist-to-height ratio along with WC. ${ }^{20}$ Though abdominal CT might appear to be a better test in predicting the abdominal adiposity, the practical possibilities of doing the imaging in all asthmatics and the advantage of point of care measurement of waist circumference makes WC the method of choice for assessing abdominal adiposity. All the above studies including the meta-analysis stress that abdominal obesity is an independent marker to be considered while measuring the anthropometric values of an asthmatic in a hospital, as they have a significant positive correlation with asthma symptom control.

There was no significant impact of gender on asthma control (two-tailed $\mathrm{p}$-value $=0.81$ ). This was contrary to the studies where they have found that females tend to have a worse perception of the day and night time symptoms than males. ${ }^{21-23}$ They also tend to report more night awakenings as compared to males. But the meta-analysis by Jiang et al. showed no gender predilection towards asthma and abdominal obesity. ${ }^{20}$ This was similar to our study where even though 51 out of 62 female patients reported partly controlled / uncontrolled asthma as against 38 of 48 male patients, it was not statistically significant.

The limitations of our study are, first, the study population was from a single geographical area and hence there is a risk in extrapolating to other Asian populations. While that is the real purpose of the study (to study the specific population - Indian, which lacks sufficient data), we cannot apply the results, at present, to other ethnic groups. Second, being a cross-sectional study, we did not assess the impact of any intervention, like weight loss, on the patient's symptom control and spirometric parameters as earlier studies have found an improvement in asthma control after weight loss. ${ }^{24,25}$ Third, the entire study population was Obese as per Indian classification (either BMI or WC criteria), and thus the results should not be extrapolated for asthmatics with normal BMI and WC.

\section{CONCLUSION}

To conclude, Indian BMI parameters have a significant correlation with asthma symptom control as compared to WHO defined global criteria. Abdominal obesity assessment by waist circumference is a simple procedure that is promising to have a significant impact on the assessment of obese asthmatics among the study population if Indian parameters are applied. Studies among other Asian populations with similar abdominal obesity risk profiles are needed to give the neces- sary impetus for precise BMI and abdominal obesity cut-offs points for the Asian population.

\section{ACKNOWLEDGEMENTS}

We would like to thank Dr. MD Ziaul and Dr. Chandrajith C- Post Graduates of our Department and Ms. Ranjitha Rajagopalan - Intern, for their technical support throughout the study period.

\section{Conflict of Interest: Nil}

Financial support: Sri Balaji Vidyapeeth Faculty Intramural Research fund

\section{Authors' Contribution:}

Vimal Raj R: Concept and design of the study, conducted the study, Analysis and Interpretation, Drafting the manuscript

Pajanivel R: Design of the study, conducted the study, Analysis, and Interpretation, Drafting the manuscript for intellectual content

\section{REFERENCES}

1. Misra A, Chowbey P, Makkar BM, Vikram NK, Wasir JS, Chadha $\mathrm{D}$, et al. Consensus statement for diagnosis of obesity, abdominal obesity and the metabolic syndrome for Asian Indians and recommendations for physical activity, medical and surgical management. J Assoc Physicians India 2009;57:163-170.

2. Beuther DA, Sutherland ER. Overweight, obesity, and incident asthma: a meta-analysis of prospective epidemiologic studies. Am J Respir Crit Care Med 2007;175(7):661-666.

3. Chen YC, Dong GH, Lin KC, Lee YL. Gender difference of childhood overweight and obesity in predicting the risk of incident asthma: a systematic review and meta-analysis. Obes Rev 2013;14(3):222-231.

4. Rönmark E, Andersson C, Nyström L, Forsberg B, Jarvholm B, Lundback B. Obesity increases the risk of incident asthma among adults. Eur Respir J 2005;25(2):282-288.

5. Camargo CA Jr, Sutherland ER, Bailey W, Castro M, Yancey SW, Emmett AH, et al. Effect of increased body mass index on asthma risk, impairment and response to asthma controller therapy in African Americans. Curr Med Res Opin 2010;26(7):16291635.

6. Mosen DM, Schatz M, Magid DJ, Camargo CA Jr. The relationship between obesity and asthma severity and control in adults. J Allergy Clin Immunol 2008;122(3):507-511.

7. Sutherland ER, Goleva E, Strand M, Beuther DA, Leung DY. Body mass and glucocorticoid response in asthma. Am J Respir Crit Care Med 2008;178(7):682-687.

8. Appleton SL, Adams RJ, Wilson DH, Taylor AW, Ruffin RE, North West Adelaide Health Study Team. Central obesity is associated with nonatopic but not atopic asthma in a representative population sample. J Allergy Clin Immunol 2006;118(6):1284 1291.

9. Chen Y, Rennie D, Cormier Y, Dosman J. Sex specificity of asthma associated with objectively measured body mass index and waist circumference: the Humboldt study. Chest 2005;128(4):3048-3054. 
10. Goudarzi H, Konno S, Kimura H, Makita H, Matsumoto M, Takei N, et al. Impact of Abdominal Visceral Adiposity on Adult Asthma Symptoms. J Allergy Clin Immunol Pract 2019;7(4):1222-1229.

11. Global Initiative for Asthma Global Strategy for Asthma Management and Prevention, 2018. [cited 2018 Apr 20]. Available from www.ginasthma.org.

12. Pellegrino R, Viegi G, Brusasco V, Crapo R, Burgos F, Casaburi R, et al. Interpretative strategies for lung function tests. Eur Respir J 2005;26(5):948-968.

13. World Health Organization. Waist circumference and waist-hip ratio report of a WHO expert consultation, Geneva, 8-11 December 2008. Geneva, World Health Org., 2011.

14. World Health Organization. Obesity: preventing and managing the global epidemic. Report of a WHO consultation. Tech Rep Ser 2000;894:i-xii, 1-253.

15. Özbey Ü, Uçar A, Çaliş AG. The effects of obesity on pulmonary function in adults with asthma. Lung India 2019;36(5):404-410.

16. WHO Expert Consultation. Appropriate body mass index for Asian populations and its implications for policy and intervention strategies. Lancet 2004;363(9403):157-163.

17. Jesus JPV, Lima-Matos AS, Almeida PCA, Lima VB, Mello LM, Souza-Machado A, et al. Obesity and asthma: clinical and laboratory characterization of a common combination. J Bras Pneumol 2018;44(3):207-212.

18. Alberti KG, Zimmet P, Shaw J. Metabolic syndrome--a new world-wide definition. A Consensus Statement from the Inter- national Diabetes Federation. Diabet Med 2006;23(5):469-480.

19. Lv N, Xiao L, Camargo CA Jr., Wilson SR, Buist AS, Strub $\mathrm{P}$, et al. Abdominal and general adiposity and level of asthma control in adults with uncontrolled asthma. Ann Am Thorac Soc 2014;11(8):1218-1224.

20. Jiang D, Wang L, Bai C, Chen O. Association between abdominal obesity and asthma: a meta-analysis. Allergy Asthma Clin Immunol 2019;15(1):16.

21. McCallister JW, Holbrook JT, Wei CY, Parsons JP, Benninger $\mathrm{CG}$, Dixon AE, et al. Sex differences in asthma symptom profiles and control in the American Lung Association Asthma Clinical Research Centers. Respir Med 2013;107(10):1491-1500.

22. Zillmer LR, Gazzotti MR, Nascimento OA, Montealegre F, Fish J, Jardim JR. Gender differences in the perception of asthma and respiratory symptoms in a population sample of asthma patients in four Brazilian cities. J Bras Pneumol 2014;40(6):591-598.

23. Ciprandi G, Gallo F. The impact of gender on asthma in the daily clinical practice. Postgrad Med 2018;130(2):271-273.

24. Dias-Junior SA, Reis M, de Carvalho-Pinto RM, Stelmach R, Halpern A, Cukier A. Effects of weight loss on asthma control in obese patients with severe asthma. Eur Respir J 2014;43:13681377.

25. Juel CT, Ali Z, Nilas L, Ulrik CS. Asthma and obesity: does weight loss improve asthma control? a systematic review. J Asthma Allergy 2012;5:21-26.

\section{Table 1: Demographic and clinical characteristics of the patients}

$\begin{array}{lc}\text { Parameter } & \text { Values } \\ \text { Age (years) } & 40.3 \pm 9.81 \\ \text { Gender } & 48(43.7 \%) \\ \text { Male } & 62(56.3 \%) \\ \text { Female } & 157.75 \pm 8.04 \\ \text { Height }(\mathrm{cm}) & 70.05 \pm 10.07 \\ \text { Weight }(\mathrm{kg}) & 28.2 \pm 4.01 \\ \text { BMI }\left(\mathrm{kg} / \mathrm{m}^{2}\right) & 58.48 \pm 11.6 \\ \% \text { predicted FEV1 } & 82.27 \pm 13.22 \\ \text { FVC } & 68.59 \pm 10.74 \\ \text { FEV1 / FVC } & \end{array}$

Values are presented as mean \pm standard deviation or number $(\%)$. FEV1, forced expiratory volume in 1 second. FVC, Forced Vital Capacity.

Table 2: BMI and asthma symptom control

\begin{tabular}{|c|c|c|c|c|}
\hline \multirow[t]{2}{*}{ Type of BMI classification } & \multirow[t]{2}{*}{ BMI criteria } & \multicolumn{2}{|c|}{ Asthma symptom control } & \multirow[t]{2}{*}{ p value } \\
\hline & & Well controlled, n (\%) & $\begin{array}{l}\text { Partly controlled/ Uncontrolled, } \\
\text { n (\%) }\end{array}$ & \\
\hline \multirow[t]{3}{*}{ Indian } & Normal & $3(2.72)$ & $2(1.81)$ & 0.042 \\
\hline & Overweight & $5(4.54)$ & $14(12.72)$ & \\
\hline & Obese & $13(11.81)$ & $73(66.36)$ & \\
\hline \multirow[t]{3}{*}{ WHO } & Normal & $8(7.27)$ & $16(14.54)$ & 0.105 \\
\hline & Overweight & $10(9.09)$ & $46(41.81)$ & \\
\hline & Obese & $3(2.72)$ & $27(24.54)$ & \\
\hline
\end{tabular}

* Fisher's exact test was used; p value $<0.05$ is statistically significant 
Table 3: WHO Waist circumference and Asthma control

\begin{tabular}{|c|c|c|c|}
\hline WHO Waist circumference & $\begin{array}{l}\text { Asthma symptom control } \\
\text { Well controlled, } \mathbf{n}(\%)\end{array}$ & $\begin{array}{c}\text { Partly controlled / Uncontrolled, } \\
\text { n (\%) }\end{array}$ & p value \\
\hline Normal & 4 & 56 & 0.69 \\
\hline Abdominal Obesity & 2 & 48 & \\
\hline
\end{tabular}

*Fisher's exact test was used;p value $<0.05$ is statisticallysignificant

Table 4: Asthma severity vs Asthma symptom control

\begin{tabular}{|c|c|c|c|c|c|c|c|}
\hline \multirow[t]{2}{*}{ FEV1 value } & \multirow{2}{*}{$\begin{array}{l}\text { Asthma spirometric } \\
\text { severity }\end{array}$} & \multicolumn{4}{|c|}{ Asthma symptom control } & \multirow[t]{2}{*}{ Odds ratio } & \multirow[t]{2}{*}{ p value } \\
\hline & & \multicolumn{2}{|c|}{ Well controlled } & \multicolumn{2}{|c|}{ Partly / Uncontrolled } & & \\
\hline \multirow[t]{2}{*}{$>60 \%$} & Mild & 7 & 17 & 20 & 45 & 4.16 & 0.0141 \\
\hline & Moderate & 10 & & 25 & & & \\
\hline \multirow[t]{3}{*}{$<60 \%$} & Moderately severe & 1 & 4 & 21 & 44 & & \\
\hline & Severe & 2 & & 21 & & & \\
\hline & Very severe & 1 & & 2 & & & \\
\hline
\end{tabular}

*Fisher's exact test was used; p value $<0.05$ is statistically significant

\section{BMI Classification and Asthma Control}

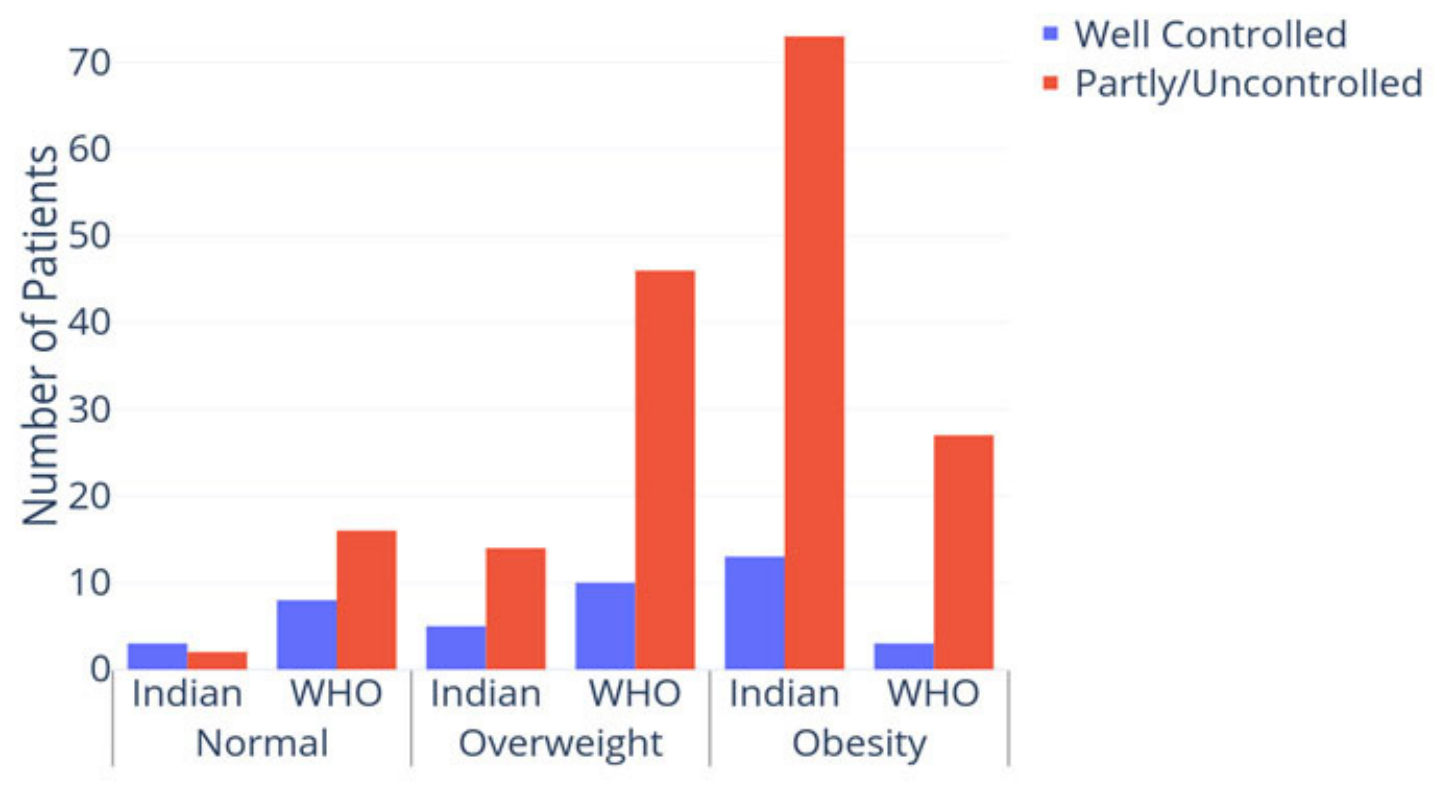

Figure 1: Relationship between Asthma control and Obesity, as per Indian BMI parameters. The probability of having partly controlled /uncontrolled asthma among obese individuals, as defined by Indian obesity criteria is found to be significant ( $p=$ 0.027 ; OR= 8.42; $95 \% \mathrm{Cl}=1.28-55.42)$ but no significant difference was noted in the overweight population ( $p=0.172 ;$ OR= 4.2; $95 \% \mathrm{Cl}=0.54-32.96)$. Based upon 4 clinical parameters, asthma control was categorized as follows: well-controlled (none of the parameters of clinical worsening were present); partly controlled (1-2 of the parameters); uncontrolled asthma (3-4 of the parameters). 
Asthma Control among WHO criteria defined normal WC patients

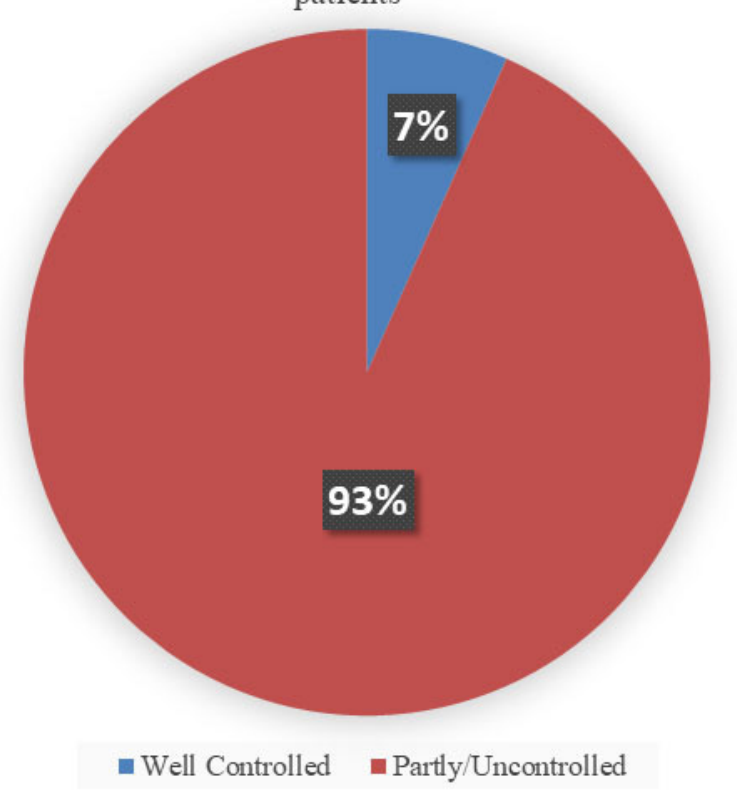

Figure 2: Relationship between Asthma control and patients with normal WC, as per WHO criteria (but has abdominal obesity as per Indian criteria). The value was not statistically significant. (Fisher exact test, two tailed $p$ value $=0.69$ ).

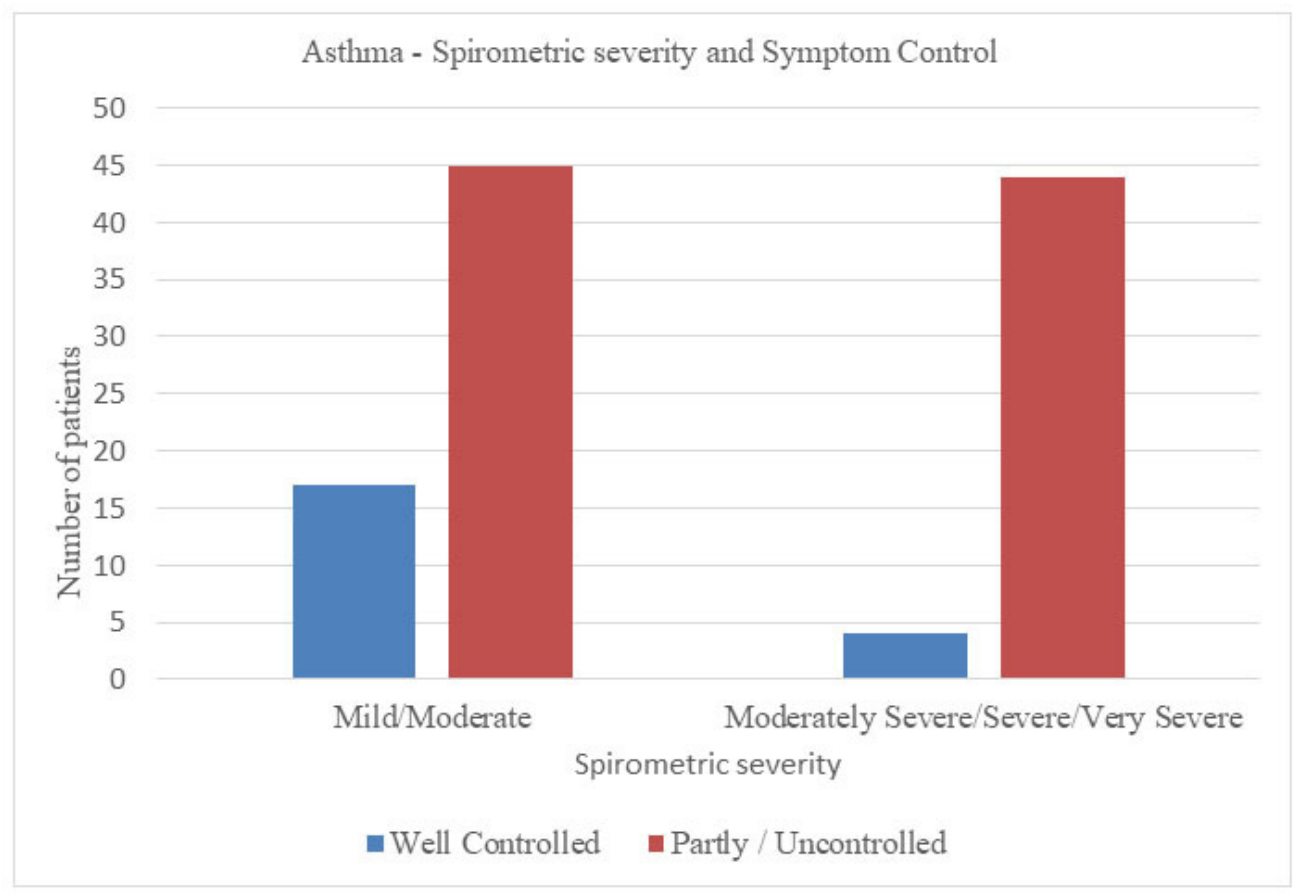

Figure 3: Relationship between severity of asthma, based on spirometric indices and asthma control. The grouping into mild/ moderate vs moderately severe/severe/very severe was based on the predicted FEV1 cut off $60 \%$ which is a risk factor for future exacerbations, as per GINA guidelines. The difference in asthma control between these two groups is found to be statistically significant $(p=0.0141 ; \mathrm{OR}=4.16 ; 95 \% \mathrm{Cl}=1.3$ to 13.33$)$. 